\title{
A UTILIZAÇÃO DA GESTÃO DO CONHECIMENTO PARA ELEVAÇÃO DE CARGO EM UMA EMPRESA CONTÁBIL
}

\section{THE USE OF KNOWLEDGE MANAGEMENT FOR LIFTING JOB IN AN ACCOUNTING FIRM}

\author{
Osmarina Pedro Garcia Garcia ${ }^{1}$; Sandra Maria Coltre ${ }^{2}$; Jean Henrique Silva ${ }^{3}$. \\ ${ }^{1}$ Universidade Estadual do Oeste do Paraná - UNIOESTE - Cascavel - Brasil \\ osmarinagarcia@hotmail.com \\ ${ }^{2}$ Universidade Estadual do Oeste do Paraná - UNIOESTE - Cascavel - Brasil \\ sandracutu1@gmail.com \\ ${ }^{3}$ União Educacional de Cascavel - UNIVEL - Cascavel - Brasil \\ jeanhenrique_10@hotmail.com
}

\begin{abstract}
Resumo
Este estudo foi elaborado em um escritório de contabilidade que aborda a importância da gestão do conhecimento para elevação de cargo, visto que os gestores têm dificuldades nos momentos de tomadas de decisão, sendo que muitas vezes optam por seguir a sua intuição que nem sempre é o caminho mais indicado. Portanto, oportunidade do treinamento com aplicação de controles internos busca-se aumentar o rendimento produtivo dos colaboradores na prestação de serviço, otimizando o rendimento do capital humano disponível na equipe. A identificação dos sistemas representacionais dos colaboradores contribuiu para a identificação do treinado que tem maior produtividade e eliminar ociosidade. A metodologia utilizada foi a descritiva, em um estudo de caso com abordagem qualitativa. Concluiu que a gestão do conhecimento é ferramenta essencial na administração do capital humano, neste estudo específico a pesquisa foi feita pela via explícita através do treinamento. Constatado que o treinamento no período de três meses, por meio de ferramentas de controle interno, a aprendizagem e o rendimento profissional dos colaboradores foi expressivo, assim a empresa pode contar sempre com um colaborador em reserva para assumir a vaga no momento adequado, facilitando o gestor na tomada de decisão de quem ele deve promover para o cargo.
\end{abstract}

Palavras-chave: gestão do conhecimento; treinamento; promoção.

\section{Introdução}

Diante do cenário de muitas empresas brasileiras que fecham antes de chegar ao seu quarto ano de existência, e de pesquisas do IBGE - Instituto Brasileiro de Geografia e Estatística (2012) que apontam, que entre as empresas que abrem, após três anos de existência, 48,2\% delas não sobreviveram, assim, é inevitável o questionamento de qual é o motivo ou circunstância que tem feito este número tornar-se tão expressivo. No entanto, o que se percebe é que nesse cenário, muitas delas têm seu insucesso devido a falhas na administração, erros na tomada de decisão, a falta de 
gestão e baixo nível de gestão de pessoas que acabam levando a empresa ao descenso. Tem ainda um agravante que é a autoconfiança excessiva, praticadas nas empresas familiares, fator que tem elevado o número de fechamento por erros na tomada de decisão dessas empresas.

Nesse interim de melhorar a gestão da organização, aborda-se a gestão do conhecimento, especificamente a via explícita por meio do fator treinamento dos colaboradores, pois, a gestão do conhecimento oferece ferramentas e formas de análise que podem auxiliar na tomada de decisão nas empresas, independentemente da complexidade da situação, ou do seu porte, haja vista, que a gestão do conhecimento beneficia o aflorar do conhecimento e consequentemente a geração de novas oportunidades. Confirmando, Nonaka e Takeuchi (1997) aduzem que a gestão do conhecimento representa a capacidade da empresa em criar um novo conhecimento, difundi-lo e incorporá-lo a produtos/serviços e pessoas/processos.

Nesta perspectiva, este estudo enfatiza a importância da gestão do conhecimento para a tomada de decisão e o entendimento de que a falta de controle leva o gestor à incerteza, que é o principal fator de erro em uma tomada de decisão. Portanto, o objetivo dessa pesquisa é: Evidenciar a utilização da gestão do conhecimento como base de tomada de decisão para promoção de colaboradores.

\section{Gestão do conhecimento}

O capital humano tende a ser o ativo mais valorizado no meio empresarial, pois nele está embutido o conhecimento, e é deste que as estratégias surgem. Em meio a um mercado tão competitivo, as empresas mais do que nunca estão procurando estratégias inovadoras e pessoas capazes de realizar tal. Neste sentido, Takeuchi e Nonaka (2008, p. 166) percebem a necessidade de investir em capital humano e expõem que, "O patrimônio indispensável para as empresas de hoje não é a fábrica e o equipamento, mas o conhecimento acumulado e as pessoas que o possuem".

É a partir da gestão do conhecimento, que as organizações agregam valores aos processos, valorizam os serviços prestados, também é possível otimizar seu potencial intelectual visando o crescimento coletivo. Probst; Raub e Romhardt (2002, p. 32) argumentam que, "A gestão do conhecimento deve ajudar os administradores em geral a tratarem o conhecimento como um recurso e deve estimular ideias práticas que possam ser implementadas".

Complementando o conceito, a gestão do conhecimento é uma metodologia de identificação, criação, renovação e aplicação dos conhecimentos estratégicos na vida da organização, isto é, a gestão do conhecimento trata da administração dos ativos do conhecimento da empresa (KANAANE e ORTIGOSO, 2001). 
A gestão do conhecimento nas organizações é o método utilizado para identificar, criar, renovar e aplicar os conhecimentos dos seus funcionários de forma estratégica na vida da empresa, trazendo vantagem competitiva (SANTOS et al, 2001).

Seguindo este pensamento inicial, e definindo a importância da gestão do conhecimento para as empresas, o que se percebe é que ela não é mais um modismo de eficiência operacional, pois atualmente ela já faz parte das estratégias da empresa, no entanto ela ainda é e aplicada como a arte de criar valor a partir dos ativos intangíveis da organização (SVEIBY, 1998).

Uma vez convencidos de que o capital humano em seu conhecimento é a maior arma estratégica de uma empresa, a certeza da geração de resultados, pode-se afirmar que o crescimento e o sucesso das empresas estão atrelados a sua capacidade de gerir talentos. Corroborando com esse pensamento Bukowitz e Willians (2002) concordam que a gestão do conhecimento é o processo pelo qual a organização gera riqueza, por meio de utilização do seu conhecimento ou capital intelectual, portanto, é através das pessoas que conduz para o caminho de geração da riqueza. É necessário, portanto, geri-las com muito empenho.

Na concepção de Pietrovski (2012) para gerar resultados, é necessário conhecer as práticas norteadoras das ações das pessoas, os elementos influenciadores e os métodos a serem utilizados no processo da geração do conhecimento. Uma ótima maneira de otimizar os processos em busca do resultado é através de ferramentas de controles internos e com uso de tecnologias avançadas ferramentas de extremo valor para organização - que ofereçam respostas concretas sobre a situação presente de um colaborador, departamento e/ou organização.

O que não deve ser esquecido é que é interessante para a empresa o uso de ferramentas tecnológicas, porém, não deve ser ponderado como ponto mais importante, pois as pessoas ainda são consideradas como prioritárias no desenvolvimento organizacional, como afirma Garcia, Garcia e Strassburg (2011, p. 4) “A gestão do conhecimento vai muito além do investimento em tecnologia ou o gerenciamento da inovação. Independente da tecnologia usada, a gestão do conhecimento depende de pessoas, da comunicação e da interatividade entre elas".

Neste contexto exposto pode-se afirmar que gerir conhecimento é o cuidado com o que há de mais precioso na empresa, é entender que tecnologia tem seu valor e pode ser adquirida facilmente, mas que é necessário ter pessoas capacitadas e bem treinadas para que a tecnologia possa surtir o efeito esperado ou estimado.

Para que esse processo entre pessoas e tecnologia funcione da melhor forma possível nas organizações, é importante lembrar as duas formas de apresentação do conhecimento. Segundo Nonaka e Takeuci, (1997, p. 67) “O conhecimento humano é criado e expandido através da interação social entre conhecimento tácito e o conhecimento explícito". 
Para melhor entendimento, a distinção entre o conhecimento tácito e o conhecimento explícito é apresentada por Nonaka e Takeuchi (1997, p. 65) quando argumentam que, “O conhecimento tácito é pessoal, específico ao contexto e, assim, difícil de ser formulado e comunicado. Já o conhecimento explícito ou codificado refere-se ao conhecimento transmissível em linguagem formal e sistemática".

Nesta pesquisa a gestão do conhecimento é abordada pela via explícita, mais especificamente pelo fator treinamento. Para confirmar a relevância do aprendizado nas empresas Davenport e Prusak (2003) argumentam que a gestão do conhecimento busca converter as informações disponíveis em conhecimento produtivo, o que favorece o aprendizado individual e coletivo favorecendo as rotinas organizacionais, o que se traduz em melhor rendimento para a empresa. No entanto a conversão de informações $m$ conhecimento produtivo acontece por meio de treinamentos aos seus colaboradores.

\subsection{Treinamento e aprendizagem para eliminar ociosidade}

O segredo de uma tarefa bem executada é um treinamento de qualidade. Através do treinamento é possível chegar com mais facilidade ao resultado desejado e ao rendimento produtivo almejado. Marras (2001) contempla que treinamento é um processo de absorção cultural e enfatiza que geralmente é em curto prazo, tem por objetivo transmitir ou reciclar conhecimento, habilidades ou atitudes relacionadas no cumprimento de tarefas e também pode ser vista na otimização do trabalho executado. Sendo assim, o treinamento é necessário para que as tarefas ou atividades sejam otimizadas e o rendimento passe a ser mais produtivo.

Para Magalhães e Andrade (2001), o treinamento pode ser visto como uma ferramenta de vital importância para o aumento da produtividade do trabalho, e também como um fator de auto satisfação do treinando, se transformando em um agente motivador, e ainda que abranja uma somatória de atividades que vão desde a aquisição de habilidade motriz de comportamentos em função de problemas amplos.

Através de treinamentos específicos, aplicados individualmente para cada colaborador, é possível chegar a oportunidades de melhoria no rendimento e muitas vezes elas somente são desenvolvidas a partir de treinamentos. Rosenberg (2002) considera que, para o conhecimento explícito, o treinamento é uma ferramenta eficaz.

Ninguém dá aquilo que não tem, da mesma forma, ninguém pode fazer bem feito aquilo que não sabe ou não aprendeu bem. Logo, para que o colaborador desempenhe bem as atividades que a ele são confiadas é necessário garantir um bom treinamento. Ainda, se no desempenho de suas atividades foi identificado alguma dificuldade maior é necessário passar por uma bateria de treinamentos específicos. 
Marras (2001) nesse sentido indica que o levantamento das necessidades básicas de treinamento do profissional responde duas questões iniciais.

1. Quem deve ser treinado?

2. O que deve ser aprendido?

Com as respostas dessas duas questões fica mais fácil a indicação do treinamento, além disso, quando as atividades do colaborador são acompanhadas por um líder de equipe ou um gestor, é detectado com facilidade alguns pontos de erros constantes. Portanto, sempre que necessário ou identificado uma oportunidade de treinamento, este deve ser feito, porém com o cuidado necessário para que o colaborador tenha a maior facilidade possível em absorver o conhecimento que a ele é externado. Na visão de Boog (2001) o treinamento se inicia com respostas as necessidades ou as oportunidades no ambiente profissional. Estabelecer valores determina que o círculo completo do processo seja cumprido, pois, focaliza as necessidades, os problemas e as oportunidades que ele originalmente visava a atender.

Com isso, cabe ao gestor enxergar as suas necessidades não apenas como um erro constante, mas como uma oportunidade de treinamento e aprendizagem. É comum que a maioria das empresas tenha dificuldades no processo de aprendizagem dos seus colaboradores, afinal envolve seres humanos, e cada um tem o seu estilo de percepção, de aprender. Senge (2009, p. 47) confirmando essa teoria, relata que, "A forma como são projetadas e gerenciadas, a maneira como os cargos são definidos e, mais importante, o modo como todos fomos ensinados a pensar e interagir [...], tudo isso cria deficiências cruciais de aprendizagem".

Diante da definição abordada, pode-se dizer que tudo que se vê, ouve ou faz, pode ser transformado em conhecimento a partir da interpretação que eles têm. Ribeiro (2006, p. 33) afirma que, "Aprender diz respeito à aquisição de novos hábitos, atitudes e comportamentos, após um treinamento específico ou novas experiências. Na realidade aprender é adquirir novas formas de conduta ou modificar formas de condutas anteriores".

A oportunidade para novas ideias advêm de mudanças dinâmicas que introduzam novas tendências, pois elas são capazes de capacitar ás pessoas e as levam a articularem novas ideias longe das restrições impostas pelas rotinas estabelecidas pela organização (PROBST; RAUB; ROMHARDT, 2002).

O que se percebe é que quando o colaborador passa por treinamento adequado, isso gera conhecimento organizacional e Segundo Nonaka e Takeuchi (1997), entende-se que a geração de conhecimento organizacional, está atrelada ao desenvolvimento da capacidade de uma empresa, em geral, de criar ou absorver novos conhecimentos, disseminá-los e incorporá-los em seus produtos, serviços e tecnologias, alcançando continuamente a inovação, o que a leva à vantagem competitiva. 
A geração de conhecimento consequentemente aguça a criatividade humana, este fato leva o colaborador à tendência de eliminar a ociosidade. Pois, a ociosidade talvez seja o grande vilão a ser combatido quando se objetiva o aumento da produtividade em uma empresa de serviços. Kohler (apud GUERREIRO e CHRISTIANS, 1992), define a capacidade ociosa de produção como o potencial produtivo não utilizado, sendo assim, é necessário identificar esses pontos de ociosidade e desenvolver estratégias para combatê-lo.

Um dos meios de identificação dos pontos ociosos está nos controles internos que objetiva a identificação de personalidade dos seus colaboradores, e a partir dos resultados obtidos de cada um, promover as mudanças ou recomendações que forem necessárias para que o rendimento produtivo não seja afetado.

Existem vários passos que a empresa pode dar para capitalizar com sucesso as diferenças individuais de personalidades. Uma das alternativas, é a utilizada nesta pesquisa, está em analisar por meio das três modalidades básica como Robbins (2009) ressalta que todo ser humano tem acesso às três modalidades ou sistemas representacionais: visual, auditivo e sinestésico. Algumas pessoas processam em seus cérebros por meio de uma estrutura visual, reagindo às cenas que veem em suas cabeças. Outras são auditivas, suas reações são por meio do que ouvem. E outras pela via sinestésica. Tais pessoas reagem com mais intensidade ao que ouvem ou sentem, unem as duas modalidades.

Sendo assim, um indivíduo pode ter um maior ou menor aprendizado em um treinamento dependendo da maneira ou da metodologia em que foi treinado, por exemplo, uma pessoa que tem seu sistema representacional visual mais aguçado, vai ter maior de dificuldade de aprender uma tarefa que é apenas falada do que um indivíduo que tem seu sistema representacional auditivo mais aguçado. $\mathrm{O}$ individuo que é visual terá mais facilidade em aprender uma tarefa se ele vir o que está sendo explicado, e ainda o sinestésico terá mais facilidade se poder palpar ou então experimentar a tarefa ensinada.

É evidente, que as técnicas de gestão precisam se adaptar a cada colaborador de acordo com seu perfil de aprendizagem, para tanto se faz necessário identificar o perfil de cada colaborador. A interpretação para aprendizagem pode se dar de maneiras diferentes em cada indivíduo. Neste sentido Wagner III e Hollenbeck (2009) aduzem que para beneficiar o conhecimento dos seus colaboradores, em primeiro lugar, a empresa deve descobrir as diferenças entre os colaboradores, e treina-los para compensar as possíveis deficiências relativas ao cargo, que são verificadas no seu perfil ou aptidões profissionais.

Esta identificação pode se dar de maneira muito simples, com simples perguntas, como por exemplo, ao perguntar como ele aprende mais nos estudos, caso a resposta seja fazendo anotações e fazendo resumos, percebe-se que ele é visual, caso a resposta seja repetindo a matéria em voz alta, 
verifica-se facilmente que ele é auditivo, e caso a resposta seja fazendo experiências praticas ou estudando em grupo, fica evidente que ele é sinestésico.

Desta maneira, é possível personalizar o treinamento, adequando o ensino e melhorando a capacidade de aprendizagem dos colaboradores, visando uma melhor absorção por parte dele. Assim consequentemente ele terá melhores condições para desempenhar sua função, tendo maior produtividade em suas tarefas. Por fim, com a utilização dos conhecimentos e talentos de seus colaboradores e a eliminação da ociosidade no trabalho, a lucratividade da empresa também tende a aumentar.

\section{Metodologia da pesquisa}

A tipologia quanto aos objetivos deste trabalho foi a descritiva. Segundo Gil (1999), a pesquisa descritiva tem como principal objetivo descrever características de determinada população ou fenômeno ou o estabelecimento de relações entre variáreis.

Já quanto aos procedimentos foi por meio de um estudo de caso. Bruyne, Herman e Schoutheete (1977) afirmam que o estudo de caso justifica a importância por reunir informações numerosas e detalhadas com vista em empreender a totalidade de uma situação.

Quanto à abordagem do problema foi a pesquisa qualitativa. Conforme Richardson (1999) os estudos que empregam uma metodologia qualitativa podem descrever a complexidade de determinado problema, analisar a intervenção de certas variáveis, compreender e classificar processos dinâmicos vividos por grupos sociais.

Os dados foram extraídos a partir de treinamentos aplicados para quatro colaboradores, com a utilização de controles internos de avaliação das atividades que foram desenvolvidas por uma equipe de funcionários da própria empresa pesquisada, na sequência na parte prática, os resultados dos controles de avaliação são apresentados em forma de quadros para melhor entendimento.

A pesquisa foi elaborada no período de janeiro a março de 2014, em uma empresa de serviços contábeis, localizado na cidade de Toledo-PR, que doravante será chama de Escritório de Contabilidade. A empresa atua no setor há 36 anos, possui 90 colaboradores em seu atual quadro de funcionários, divididos em 10 equipes, o estudo se dá especificamente na equipe de treinamentos, com ênfase na vaga para o setor fiscal/contábil. No entanto, a empresa oferece treinamento constante para todos os setores e atua com quantidade variada de colaboradores em treinamento, isso é definido conforme a necessidade de cada setor.

A equipe de treinamentos é composta por um colaborador que é o líder, um colaborador que efetua o treinamento e outros quatro colaboradores que são treinados constantemente para aprender as atividades rotineiras dos setores, neste caso específico o fiscal/contábil. 
O treinamento tem a duração de três meses, portanto, cada vez que se encerra um ciclo de treinamento, já se inicia o próximo, o que faz a empresa sempre ter alguém preparado para assumir a função, este fator justifica que o treinamento seja feito sempre com quatro colaboradores de cada vez, bem como, a facilidade de treinar poucas pessoas de cada vez, pois se percebe que a atenção dada pelo treinador para cada um dos colaboradores é satisfatória, sendo que para um volume maior de treinados o resultado poderia não ser o mesmo.

O objetivo principal deste processo é sempre manter colaboradores devidamente treinados e preparados para assumir cargos na empresa para quando houver vagas e, esta quantidade de treinados supre a necessidade da empresa. Aqui especificamente, o colaborador que apresentar melhor rendimento tem a vantagem na escolha para ser promovido a uma equipe fiscal/contábil. O escritório possui um sistema próprio para lançamentos fiscais e contábeis, sendo este um diferencial sobre seus concorrentes.

\section{Caso prático}

Os quatro colaboradores participantes da pesquisa são treinados com base nas atividades rotineiras da contabilidade, bem como lançamentos fiscais e contábeis, procura-se chegar ao mais próximo possível da realidade de uma equipe fiscal/contábil, o objetivo é que quando for necessário um destes colaboradores em treinamento vir a integrar uma equipe fiscal/contábil, ele esteja preparado.

Logo que o colaborador torna-se membro da equipe, ele passa pelo treinamento inicial, onde aprende como funciona o sistema, a sequência dos lançamentos, como conferir o balancete, técnicas de atendimento telefônico e pessoal, aprende ainda as normas da equipe e da empresa.

Após passar pelo período de treinamento inicial, ele inicia de forma prática as atividades no contexto da equipe, efetuando os lançamentos de acordo com as orientações do colaborador que está o treinando. Porém, antes mesmo de iniciar os treinamentos é aplicado um questionário para o colaborador, e ainda ele passa por uma entrevista para que seja identificado se o sistema representacional do colaborador é visual, auditivo ou sinestésico.

Neste estudo, os indivíduos são tratados como visuais, auditivos ou sinestésicos, assim é possível entender se a metodologia em que o colaborador é treinado ou gerido, está de maneira íntima atrelada ao sucesso na aplicação de seus esforços e seu conhecimento na prestação do serviço.

Identificando seu sistema representacional, o referido treinamento é adaptado para cada colaborador, visando à facilidade no entendimento e compreensão das atividades que ele terá de cumprir. Portanto, a partir da aplicação deste questionário é possível identificar o perfil de 
aprendizagem de cada colaborador e assim se torna possível um treinamento personalizado para cada um, maximizando assim o êxito no treinamento.

Depois de identificado o perfil de aprendizagem através do seu sistema representacional e devidamente treinado, os colaboradores iniciarão os lançamentos que serão acompanhados por um formulário de controle interno, que tem a função de oferecer informações de quem é o colaborador mais produtivo, assim, tem como saber qual deles faz a maior quantidade de lançamentos contábeis dentro do mês e ainda quem é o colaborador que mais perde tempo com retrabalhos devido aos erros cometidos e também o colaborador que perde tempo com conversa ou atividades extra profissional, como por exemplo, consultas pessoais na internet.

Após uma analise dos erros dos colaboradores, pode-se verificar se alguém tem mais dificuldade com algum tipo de lançamento, ou então, se é por falta de atenção, ou dificuldades de entendimento e assim podem surgir oportunidades de treinamentos, estes treinamentos são denominados: treinamentos de correção. Depois de aplicados os treinamentos de correção, os erros diminuem, logo, o tempo perdido com retrabalho é reduzido, aumentando assim a quantidade de lançamentos contábeis feitos pelos colaboradores, sendo eles mais produtivos o resultado final também aumenta.

Com base, nos periódicos treinamentos de avaliação, acompanhados pelo controle de avaliação e posteriormente seus resultados compilados de forma visível como apresentados nos quadros na sequência, a qualquer momento pode-se identificar quem é o colaborador mais produtivo, portanto, na oportunidade em que surgir uma vaga em uma equipe fiscal/contábil, o gestor pode eliminar o "achismo" e utilizar-se dos controles para tomar uma decisão acertada e com segurança acerca de qual colaborador promover.

A durabilidade do treinamento é de três meses. No início do primeiro mês faz-se a identificação do sistema representacional de cada um dos treinados. Neste casso específico ao iniciarem na equipe, conforme mostra o Quadro 1, foi identificado o seguinte sistema representacional em cada um dos colaboradores.

Quadro 1 - Sistema representacional dos colaboradores em treinamento

\begin{tabular}{|c|c|}
\hline Colaborador & Sistema representacional \\
\hline $\mathrm{X}$ & Visual \\
\hline $\mathrm{Y}$ & Visual \\
\hline $\mathrm{Z}$ & Auditivo \\
\hline $\mathrm{W}$ & Sinestésico \\
\hline
\end{tabular}

Fonte: Dados da pesquisa (2014)

Logo, evidencia que os colaboradores X e Y são visuais, o colaborador Z é auditivo e o colaborador W é sinestésico. Assim sendo, os treinamentos para eles foram adaptados de maneira diferente, buscando um maior e mais rápido absorvimento do conteúdo por parte dos colaboradores. 
Para os colaboradores visuais, foi entregue uma apostila autoexplicativa, sobre a maneira de como realizar os lançamentos. Após uma boa leitura, o colaborador responsável pelo treinamento fez repetidos lançamentos no sistema para que os treinados o visualizassem. Após isso, os dois colaboradores de percepção visual iniciaram os lançamentos de maneira individual, cada um em seu computador.

Para o colaborador auditivo, foi entregue um arquivo de áudio com uma explicação detalhada sobre como realizar os lançamentos, após ter escutado algumas vezes, o colaborador responsável pelos treinamentos novamente explicou verbalmente como realizar os treinamentos e apresentou o sistema para o colaborador. Em seguida, o colaborador de percepção auditiva iniciou os lançamentos em seu computador.

Para o colaborador sinestésico, o treinador apresentou o sistema com alguns lançamentos já efetuados e o deixou livre por alguns minutos para desbravar o sistema do seu modo particular e, em seguida, foi explicando passo a passo como realizar os lançamentos e o colaborador no mesmo tempo ia realizando os lançamentos no sistema. Após isso, o colaborador em treinamento continuou a realizar sozinho os lançamentos em seu computador de trabalho.

Os resultados obtidos no primeiro mês de lançamentos estão apresentados no Quadro 2.

Quadro 2 - Resultados de lançamentos no primeiro mês de treinamento

\begin{tabular}{|c|c|c|}
\hline Colaborador & Lançamentos feitos & Erros cometidos \\
\hline $\mathrm{X}$ & 55 & 15 \\
\hline $\mathrm{Y}$ & 50 & 15 \\
\hline $\mathrm{Z}$ & 57 & 19 \\
\hline $\mathrm{W}$ & 51 & 10 \\
\hline
\end{tabular}

Fonte: Dados da pesquisa (2014)

Primeiramente, percebe-se com clareza um equilíbrio entre os quatro colaboradores, tanto na quantidade de lançamentos feitos, quanto na quantidade de erros cometidos, justificando a eficácia do treinamento, pois, os quatro colaboradores com sistemas representacionais diferentes tiveram aprendizagem equivalente, tendo recebido o treinamento de maneiras diferentes, adaptada para cada um conforme seus sistemas representacionais.

Em um segundo momento, verifica-se que existem alguns erros nos lançamentos dos colaboradores em treinamento, portanto é necessária uma estratégia para minimizar estes números. O líder da equipe analisou criticamente cada erro cometido, fez um feedback individual com cada colaborador em treinamento e apontou onde estavam concentrados seus erros, inclusive os momentos de ociosidades onde perdiam a concentração nas atividades profissionais em detrimento a conversas pessoais na internet. $O$ treinador os instruiu como deveriam fazer os lançamentos a partir daquele momento.

Ainda, foi feito um treinamento de fixação, para que os erros cometidos não se repetissem. Este treinamento, como já mencionado foi específico para cada colaborador, independente de onde 
e como estavam concentrados seus erros, os treinamentos foram feitos de maneira diferente para cada sistema representacional.

Passados alguns dias de intervalos, entre a primeira e a segunda fase de treinamento, deu-se início a nova etapa. Os colaboradores continuaram o treinamento no segundo mês reiniciando os lançamentos, tendo o cuidado pedido no feedback e com o acompanhamento do colaborador responsável pelos treinamentos.

No segundo mês os resultados obtidos foram os apresentados no Quando 3.

\begin{tabular}{|c|c|c|}
\multicolumn{2}{|c|}{ Quadro 3 - Resultados de lançamentos no segundo mês de treinamento } \\
\hline Colaborador & Lançamentos feitos & Erros cometidos \\
\hline X & 76 & 5 \\
\hline Y & 71 & 13 \\
\hline Z & 65 & 7 \\
\hline W & 83 & 5 \\
\hline
\end{tabular}

Fonte: Dados da pesquisa (2014)

Neste quadro percebe-se uma melhora significativa na quantidade de contabilidades feitas, mas principalmente na diminuição dos erros cometidos, isso significa que o treinamento do primeiro para o segundo mês deu resultado positivo.

Novamente, despois de uma pausa entre a segunda e a terceira etapa, no terceiro mês, reiniciando o treinamento, foi seguido o mesmo procedimento dos meses anteriores e também foi usado o feedback individual. Os resultados obtidos estão apresentados no Quadro 4.

Quadro 4 - Resultados de lançamentos no segundo mês de treinamento

\begin{tabular}{|c|c|c|}
\hline Colaborador & Lançamentos feitos & Erros cometidos \\
\hline X & 81 & 4 \\
\hline Y & 69 & 8 \\
\hline Z & 68 & 6 \\
\hline W & 92 & 5 \\
\hline
\end{tabular}

Fonte: Dados da pesquisa (2014)

Constatou assim, uma progressiva melhora nos resultados apresentados pelos colaboradores. Caso, neste momento surgisse uma vaga em alguma equipe fiscal/contábil, o gestor teria um embasamento seguro e confiável, conforme esta metodologia utilizada pela empresa, a respeito de cada colaborador em treinamento para saber quem é o mais preparado naquele momento para integrar a equipe fiscal/contábil e assim suprir a necessidade.

Analisando os resultados obtidos nos três meses de treinamento, é possível visualizar o retrospecto final de cada colaborador em treinamento no Quadro 5. 
Quadro 5 - Resultados de lançamentos no terceiro mês de treinamento

\begin{tabular}{|c|c|c|}
\hline Colaborador & Lançamentos feitos & Erros cometidos \\
\hline X & 212 & 28 \\
\hline Y & 190 & 24 \\
\hline Z & 190 & 40 \\
\hline W & 226 & 23 \\
\hline
\end{tabular}

Fonte: Dados da pesquisa (2014)

Assim, com clareza conclui que o colaborador W é o mais preparado para assumir a vaga da equipe fiscal/contábil, pois ele foi quem obteve a maior quantidade de lançamentos contábeis feitos e ainda o menor índice de erros no período de treinamento que foi de três meses, facilitando assim a decisão do gestor na escolha do melhor colaborador para promoção.

É inevitável afirmar, que caso não tivesse sido identificado o sistema representacional dos colaboradores no início do processo, possivelmente os treinamentos teriam sido idênticos e algum colaborador poderia ter sido prejudicado. Ainda, se não tivesse sido adotada a prática do controle interno no acompanhamento com os colaboradores em treinamento para focar seu conhecimento em busca do resultado, possivelmente não haveria uma diminuição dos erros e da ociosidade, como resultado de uma melhora progressiva tão visível.

Com este método o gestor pode administrar seus talentos, assim, focando o conhecimento em busca de um resultado almejado, facilitando a qualquer momento a segurança em uma tomada de decisão, onde seja necessário saber qual dos colaboradores em treinamento é o mais preparado, ou, o menos preparado, quem ele pode promover ou, quem demitir, e em quem investir. Estas interrogativas são respondidas facilmente pelo gestor a partir do método de treinamento utilizado pela empresa, que compõe a via explícita da gestão do conhecimento.

\section{Considerações Finais}

Este estudo procurou demonstrar a necessidade de gerir a gestão do conhecimento dos recursos humanos de uma empresa, a importância de gerir o conhecimento dos colaboradores pela via explícita por meio de treinamentos, portanto, o objetivo centro da pesquisa é de evidenciar a utilização da gestão do conhecimento como base de tomada de decisão para promoção de colaboradores.

A fim de garantir que o objetivo proposto fosse cumprido, foi identificado o perfil de aprendizagem de cada colaborador, a partir de perguntas específicas e análise de suas respostas, a fim de compreender o sentido predominante no colaborador, para então aplicar os treinamentos de maneira mais proveitosa.

Ficou evidente, a oportunidade de treinamentos com a aplicação do controle interno de avaliação, a fim de diminuir os erros de lançamentos por parte dos colaboradores da equipe e assim eliminar ou pelo menos diminuir o retrabalho. Bem como, alguns pontos de ociosidade também 
foram identificados por meio do controle interno de avaliação, nos momentos que estavam ociosos eles buscavam a internet para conversas pessoais e perdiam a concentração nas suas atividades. O controle de avaliação foi utilizado para acompanhamento mais próximo, objetivando a eliminação destes pontos e garantindo o aumento na produtividade.

Observou-se claramente que a aplicação do controle interno de avaliação é uma ferramenta eficaz na gestão do conhecimento no fator de treinamentos, pois o objetivo desta pesquisa só pôde ser cumprido após a sua aplicação, que foi um instrumento de identificação dos pontos de análise para a tomada de decisão.

Constatou-se a importância da gestão do conhecimento para a tomada de decisão, a tranquilidade que o gestor passa a ter quando se tem resultados seguros. Esses procedimentos geram o aumento da produtividade, que é apenas um reflexo da gestão do conhecimento na organização, com a aplicação de controle interno de avaliação e na identificação da melhor maneira de abordar e treinar os colaboradores.

Conclui-se, que a gestão do conhecimento, no caso específico desta pesquisa pela via explícita, é ferramenta essencial na administração do capital humano, especificamente no treinamento. Pois, aqui foi constatado que o treinamento no período de três meses, por meio de ferramentas de controle interno de avaliação, a aprendizagem e o rendimento profissional dos colaboradores foram expressivos, assim a empresa pode contar sempre com um colaborador em reserva para assumir a vaga no momento adequado. Destarte, conforme mostra este estudo, quando é feito o treinamento específico à necessidade do sistema representacional do indivíduo, é perceptível à melhora nos resultados. Pois, o rendimento dos colaboradores foi progressivo e gradual, com isso, o que se percebe é que houve realmente a construção da aprendizagem, fato que beneficia o indivíduo em termos de ganho de conhecimento e consequentemente o resultado produtivo da empresa.

Não querendo esgotar esse assunto, fica as recomendações para novas pesquisas tanto na via tácita que não foi o caso desse estudo como na via explicita em outros fatores da gestão do conhecimento.

\footnotetext{
Abstract

This study was designed in an accounting firm that addresses the importance of knowledge management for lifting charge, since managers have difficulties in times of decision-making, and often choose to follow their intuition, which is not always the most appropriate way. Therefore, the opportunity of training with application of internal controls seeks to increase the productive output of employees in service delivery, optimizing the performance of human capital available in the team. The identification of representational systems of employees contributed to the identification of the trained that had more productivity and eliminating idle. The methodology used was descriptive, in a case study with a qualitative approach. Concluded that knowledge management is an essential tool in the management of human capital, in this particular study the research was done
} 
by the explicit route through the training. It was found that three months of training, through internal control tools, learning and professional performance of employees was significant, so the company can always count on a collaborator in reserve to take the job at the right time, facilitating the manager in making the decision of whom he should promote to the position.

Keywords: knowledge management; training; promotion.

\section{Referências}

BOOG, G. G. (coord.). Manual de Treinamento e Desenvolvimento: um guia de operações - manual oficial da ABTD. São Paulo: Makron Books, 2001.

BRUYNE, P. de; HERMAN, J.; SCHOUTHEETE, M. de. Dinâmica da pesquisa em ciências sociais: os polos da prática metodológica. Rio de Janeiro: F. Alves, 1977.

BUKOWITZ, W. R.; WILLIAMS, R. L. Manual de gestão do conhecimento: ferramentas e técnicas que criam valor para a empresa. Porto Alegre: Bookman, 2002.

DAVENPORT, T; PRUSAK, L. Conhecimento Empresarial como as Organizações Gerenciam o seu Capital Intelectual. Métodos e Aplicações Práticas. 18 ed. Trad. de Lenke Peres. Rio de Janeiro: Campus, 2003.

GARCIA, E.; GARCIA, O. P. G.; STRASSBURG, U. Discussão sobre a utilização da gestão do conhecimento como fator determinante para a criação e retenção de talentos nas organizações. IN CONGRESSO INTERNACIONAL DE ADMINISTRAÇÃO. UEPG - UNIVERSIDADE ESTADUAL DE PONTA GROSSA. GESTÃO ESTRATÉGICA: INOVAÇÃO COLABORATIVA E COMPETITIVIDADE. Anais ... Ponta Grossa: 19 a 23 de setembro de 2011.

GIL, A. C. Métodos e técnicas de pesquisa social. 5. São Paulo: Atlas, 1999.

GUERREIRO, R. N.; CHRISTIANS, R. L. M. O tratamento da ociosidade - análise das implicações contábeis e fiscais. XVI Congresso Brasileiro de Contabilidade. Volume II. Salvador - BA, 1992.

IBGE - Instituto Brasileiro de Geografia e Estatística. $48 \%$ das empresas brasileiras fecham as portas depois de três anos. Disponível em: <http://www.sebraepr.com.br/PortalInternet/Noticia/ci.48\%25-das-empresas-brasileiras-fechamas-portas-depois-de-tr\%C3\%AAs-anos.print>. Publicado em: 27 ago. 2012. Acessado em 06 mai. 2014.

KANAANE, R.; ORTIGOSO, S. A. F. Manual de treinamento e desenvolvimento do potencial humano. São Paulo: Atlas, 2001.

MAGALHÃES, M. L.; ANDRADE, J. E. B.. Auto e hetero-avaliação no diagnóstico de necessidades de treinamento: Estudos de Psicologia, 2001. crossref

MARRAS, J. P. Administração de Recursos Humanos: do operacional ao estratégico. 3.ed. São Paulo: Futura, 2001.

NONAKA, I.; TAKEUCHI, H. Criação de conhecimento na empresa. Trad. de Ana Beatriz Rodrigues, Pricilla Martins Celeste. 19 ed. Rio de Janeiro: Elsevier, 1997.

PIETROVSKI, E. F. A gestão do conhecimento e a cooperação universidade empresa. Dissertação (Mestrado em Engenharia de Produção, área Gestão de Negócios) - UFSC, Florianópolis - SC. 2012.

PROST, G.; RAUB, S.; ROMHARDT, K. Gestão do conhecimento: os elementos construtivos do sucesso. Porto Alegre: Artmed, 2007.

RIBEIRO, A. de L. Gestão de Pessoas. São Paulo: Saraiva, 2006.

RICHARDSON, R. J. Pesquisa social: métodos e técnicas. 3. ed. São Paulo: Atlas, 1999.

ROBBINS, A. Poder sem limites: o caminho do sucesso pessoal pela programação neurolinguística. Rio de Janeiro: Saraiva, 2009. 
ROSENBERG, M. J. E-learning: implementando com sucesso aprendizado on-line na sua empresa. São Paulo: Makron Books, 2002.

SANTOS, A. R. dos; et al (Org.). Gestão do Conhecimento: uma experiência para o sucesso empresarial. Curitiba. Ed. Universitária Champagnat. 2001. Disponível em: 〈http://www1.serpro.gov.br/publicacoes/gco_site/index.htm>. Acesso em: 13 jul. 2014.

SENGE, P. M. A quinta disciplina: Arte e prática da organização que aprende. Trad. Gabriel Zide Neto. 25. ed. Rio de Janeiro: BestSeller, 2009.

SVEIBY, K. E. A nova riqueza das organizações. Rio de Janeiro: Campus, 1998.

TAKEUCHI, H.; NONAKA, I. Gestão do conhecimento. Trad. Ana Thorell. Porto Alegre: Bookman, 2008.

WAGNER III, J. A.; HOLLENBECK, J. R. Comportamento Organizacional: criando vantagem competitiva. Trad. Cid Knipel Moreira; 2. ed. São Paulo: Saraiva, 2009.

\section{Dados dos autores}

\section{Nome completo: Osmarina Pedro Garcia Garcia}

Filiação institucional: Universidade Estadual do Oeste do Paraná - UNIOESTE

Departamento: Programa de Pós-Graduação em Gestão e Desenvolvimento Regional - PPGGDR Função ou cargo ocupado: Discente

Endereço completo para correspondência: R: Rio de Janeiro 1405, Apto 402, Centro - CEP: 85801030 Cascavel - PR - Brasil

Telefones para contato: (45) 3224-3475

e-mail: osmarinagarcia@hotmail.com

\section{Nome completo: Sandra Maria Coltre}

Filiação institucional: Universidade Estadual do Oeste do Paraná - UNIOESTE

Departamento: Programa de Pós-Graduação em Gestão e Desenvolvimento Regional - PPGGDR

Função ou cargo ocupado: Docente

Endereço completo para correspondência: R: São Paulo 500, Apto 1202, Centro - CEP: 85801-020

Cascavel - PR - Brasil

Telefones para contato: (45) 9971-2709

e-mail: sandracutu1@gmail.com

Nome completo: Jean Henrique Silva

Filiação institucional: União Educacional de Cascavel - UNIVEL - Cascavel - Brasil

Departamento: Programa de Pós-Graduação

Função ou cargo ocupado: Discente

Endereço completo para correspondência: R: Carlos Sbaraine nº 5773, Centro - CEP: 85915-000

Toledo - PR - Brasil

Telefones para contato: (45)9128-0373 
e-mail: jeanhenrique_10@hotmail.com

Submetido em: 08/09/2014

Aceito em: 17/12/2014 